\title{
O PORTUGUÊS BRASILEIRO EM GRAMÁTICAS DO FINAL DO SÉCULO XIX (1880-1890): UMA ANÁLISE DE DADOS SINTÁTICOS NO PERÍODO CIENTÍFICO
}

\author{
THE BRAZILIAN PORTUGUESE AMIDST 19TH CENTURY GRAMMARS (1880- \\ 1890): ANALYZING SYNTHETIC DATA FROM THE SCIENTIFIC PERIOD
}

\author{
José Eric da Paixão Marinho ${ }^{1}$
}

\begin{abstract}
RESUMO: A discussão sobre a existência de uma norma brasileira não é algo recente. No que diz respeito à gramaticografia brasileira, Cavaliere (2014) e Coelho et al. (2014) apontam para a aparição das especificidades do português brasileiro nas gramáticas produzidas no período dito "científico" no Brasil, entre 1880 e 1920. Gramáticos deste período, como Júlio Ribeiro (1881), João Ribeiro (1887) e Pacheco \& Lameira (1887), motivados por fatores políticos, sociais e linguísticos, já assinalavam a existência das particularidades da língua dos brasileiros em suas obras. Desta forma, este trabalho tem como objetivo analisar como gramáticas produzidas na primeira década do período "científico" abordam as especificidades sintáticas do português do Brasil do século XIX. Para alcançar tal objetivo, será utilizado o arcabouço teórico-metodológico da Historiografia da Linguística, com base nos textos de Swiggers (2009; 2013) e Murray (1994), para a análise das gramáticas selecionadas para este estudo. Os resultados mostram que, apesar de uma crescente aparição das especificidades do português falado no Brasil nas fontes selecionadas, o tratamento dado a tais especificidades, em sua maioria, configura-se de modo proibitivo e a partir de uma perspectiva de inferioridade à norma lusitana, prescrita e idealizada.
\end{abstract}

PALAVRAS-CHAVE: Português Brasileiro. Gramáticas. Período científico.

ABSTRACT: The discussion about the existence of a Portuguese language from Brazil is not recent. With regard to Brazilian grammar, Cavaliere (2014) and Coelho et al. (2014) point to the appearance of the first syntactic data of Brazilian Portuguese in grammars produced in the so-called "scientific" period, between 1880 and 1920. Grammars of this period, such as Júlio Ribeiro (1881), João Ribeiro (1887), and Pacheco \& Lameira, motivated by political, social and linguistic factors, already pointed to the existence of the particularities of the language of Brazilians in their works. Thus, this work aims to analyze how grammars produced in the first decade of the "scientific" period address the syntactic specificities of 19th century Brazilian Portuguese. To achieve this goal, the theoretical-methodological framework of Historiography of Linguistics will be used, based on the texts of Swiggers $(2009 ; 2013)$ and Murray (1994), for the analysis of the grammars selected for this study. The results show that, despite a growing rhetoric in favor of language evolutionary processes and a greater appearance of the specificities of Brazilian Portuguese in the selected sources, the syntactic treatment given to such specificities is mostly prohibitive and from a perspective of inferiority to the prescribed and idealized Lusitanian norm.

KEYWORDS: Brazilian Portuguese. Grammars. Scientific period.

\section{Introdução}

O recorte linguístico adotado por uma nação, que será utilizado com fins de reger as interações sociais do cotidiano, surge como um reflexo das relações identitárias existentes entre a população. Neste contexto, o estabelecimento de uma língua nacional está diretamente ligado ao conceito de gramatização. De acordo Auroux (1992), a gramatização de uma língua pode ser entendida como um "processo que conduz a descrever e instrumentar uma língua na base de duas tecnologias, que são ainda hoje os pilares de nosso saber metalinguístico: a gramática

\footnotetext{
${ }^{1}$ Mestre em Linguística pela Universidade Federal da Paraíba (UFPB/PROLING). Endereço eletrônico: eric_11jp@hotmail.com
} 
e o dicionário" (p. 65). Além disso, o autor chama atenção para o fato de que este é um processo orientado pela vontade de conduzir uma variedade linguística a uma variedade linguística de prestígio, através da produção dos instrumentos linguísticos.

Nesta perspectiva, autores da segunda metade do século XIX já discutiam sobre a construção de língua nacional brasileira. De acordo com Albuquerque \& Cox (1999), como resultado do processo político e social que perpassava o país naquela época, as discussões sobre a língua portuguesa do Brasil resultaram nos embates entre separatistas e legitimistas. Neste ponto de vista, os separatistas, cientes das questões de léxico, sintaxe e morfologia, defendiam a diferenciação entre as línguas portuguesa do Brasil e de Portugal com objetivo de apresentar o português do Brasil como a língua oficial do país. Em contrapartida, os legitimistas visavam conservar o português clássico, ignorando, assim, as especificidades do português do Brasil da segunda metade do século XIX.

Neste contexto, o novo modelo gramatical que surgia no Brasil no final do século XIX, o histórico-comparativo, também acentuou as discussões em torno da existência de uma língua dos brasileiros. Este novo modelo compreende e aceita o processo de evolução e o apresenta como algo natural às línguas, diferindo do modelo que o precedeu, o racionalista, que prezava pela relação convencionada entre pensamento perfeito e língua perfeita, desconsiderando, assim, os processos evolutivos e de mudanças por que as línguas passavam.

A partir dessa nova visão do fazer gramatical, em 1881, é publicada a Grammatica Portugueza, de Júlio Ribeiro. A obra de Ribeiro foi a primeira gramática brasileira a abordar especificidades sintáticas da língua portuguesa do Brasil. Dessa forma, ao objetivarmos tomar as primeiras especificidades sintáticas do português do Brasil mencionadas em gramáticas como objeto de estudo para este artigo, optamos por privilegiar gramáticas produzidas a partir de 1881, quando inaugura-se o período denominado científico, até o final desta década (18801890).

Considerando esses fatos, com este trabalho pretendemos contribuir com novos saberes para os estudos sobre língua portuguesa do Brasil, linguagem e gramática, com perspectiva histórica ou não, visto que este tipo de estudo "confere ao pesquisador o necessário discernimento para distinguir entre conquistas científicas efetivamente relevantes e teses inconsistentes ou desprovidas de fundamentação sólida" (CAVALIERE, 2014, p. 7).

A presente pesquisa teve como objetivo analisar como gramáticas produzidas na primeira década do período dito "científico" abordam em nível retórico e gramatical as especificidades sintáticas do português do Brasil do século XIX.

\section{Um modelo para interpretação dos dados retóricos: a historiografia da linguística e retórica revolucionária}

De acordo com Swiggers (2009, 2013), a Historiografia da Linguística é um campo interdisciplinar; assim, utiliza-se de contribuições oriundas de outras áreas do conhecimento para realizar a análise dos seus objetos de estudo de maneira mais profunda e confiável. Nesta perspectiva, a Historiografia da Linguística preocupa-se em analisar como se deu a produção, o desenvolvimento ou o esquecimento de um determinado conhecimento linguístico ao longo da história. Desta forma, as contribuições oriundas de outras áreas de conhecimento, como a filosofia das ciências, são de grande valia para que o historiógrafo possa refletir e entender sobre esses processos de conservação e mudança que ocorreram durante a história de uma determinada ciência, neste caso a Linguística.

Desta maneira, por almejarmos analisar o nível retórico apresentado nas gramáticas selecionadas para pesquisa, utilizaremos o conceito de retórica revolucionária cunhado por Murray (1994). Segundo o autor, a retórica revolucionária almeja romper com as ideias e as 
hipóteses de trabalhos anteriores. $\mathrm{O}$ autor subdivide esse conceito em: retórica de continuidade e retórica de ruptura.

De acordo com o autor, "a retórica revolucionária parece apelar para os entusiasmos de uma nova geração (sem interesse na velha perspectiva e com pouco conhecimento sobre a perspectiva anterior), para um trabalho significativo e original ${ }^{2 \prime}$ (MURRAY, 1994, p. 245). Sendo assim, o autor defende que, ao trabalhar com essas proposições, o historiógrafo deve analisar a retórica apresentada pelo autor da obra investigada a fim de verificar se estas apresentam uma retórica de continuidade e acumulação com a tradição de pesquisa em vigência no período, ou se apresentam uma retórica de ruptura propondo-se a romper com uma tradição de pesquisa, oferecendo, assim, novas proposições e critérios para solução de problemas.

Vale salientar que, para a realização desta pesquisa, nos utilizaremos dos conceitos propostos por Murray (1994), por almejarmos verificar se as gramáticas "científicas" dessa nova corrente produzidas no Brasil a partir do século XIX - desenvolvidas sob uma perspectiva naturalista, diacrônica, histórico-comparativa, linguística - rompem, em nível retórico e gramatical, com o modelo gramatical que as precedem ou se permanecem apresentando as especificidades sintáticas do português do Brasil a partir de um viés prescritivo e idealizador.

\section{Metodologia}

Para selecionar as fontes desta pesquisa mapeamos as gramáticas publicadas no século XIX. Além disso, realizamos um percurso pré-analítico nas obras produzidas antes do período científico às quais tivemos acesso, na busca de possíveis menções à sintaxe do português do Brasil, para, assim, decidirmos a periodização a ser adotada. Como não foram encontradas menções significativas de nível sintático nestas obras, optamos por analisar gramáticas produzidas na primeira década do período científico para discutirmos as primeiras aparições sintáticas do português do Brasil em gramáticas.

Desta forma, decidimos analisar as seguintes obras publicadas na penúltima década do século XIX:

1- RIBEIRO, J. Grammatica Portugueza, 1881;

2- RIBEIRO, J. Grammatica Portugueza: $3^{\circ}$ anno, 1889[1887];

3- PACHECO DA SILVA JR., M; LAMEIRA DE ANDRADE, Noções de grammatica portugueza, 1887;

Após a escolha das gramáticas, foi realizada uma leitura exaustiva nestas obras a fim de mapearmos os fenômenos sintáticos do português do Brasil abordados. Estes dados serviram de objeto para a nossa a análise.

Desta maneira, durante a realização da nossa análise observaremos os seguintes aspectos: 1) nível retórico, observaremos as abordagens utilizadas pelos gramáticos e, quando possível, os seus entendimentos sobre a língua portuguesa do Brasil; e 2) nível descritivo, observaremos se as especificidades sintáticas do português do Brasil mapeadas são apresentadas de maneira neutra (descritiva), positiva ou negativa (valorativas), para analisarmos se há compatibilidade com o fazer gramatical proposto em nível retórico.

\section{A análise do nível retórico: a abordagem do português do Brasil}

Nesta seção observaremos a retórica adotada pelos gramáticos selecionados para verificarmos as abordagens utilizadas nas obras e os entendimentos sobre a língua portuguesa

\footnotetext{
2"Revolutionary rhetoric seems to appeal to the enthusiasms of a new generation (with no stake in the old perspective on little knowledge of it) for meaningful and original work" (MURRAY, 1994, p. 245, tradução nossa).
} 
Volume 15 - Número 1 - jan/jul de 2020

do Brasil apresentados. Para termos uma visão mais apurada deste nível, decidimos analisar cada gramática individualmente.

\title{
4.1 Grammatica Portugueza (1881), de Júlio Ribeiro
}

É plausível apontar que a Grammatica Portugueza, de Júlio Ribeiro, publicada em 1881, ficou conhecida por inaugurar uma nova corrente gramatical no Brasil, a histórico-comparativa, inspirando-se nos estudos linguísticos que estavam em voga na Europa naquele período.

No início da gramática, durante a seção de introdução, Ribeiro (1881) apresenta uma definição de gramática. Segundo o autor, "grammática é a exposição methodica dos factos da linguagem" (p. 1). Desta forma, nesse primeiro momento da obra, ao tratar o fazer gramatical como exposição dos fatos da linguagem, é perceptível que o autor já apresenta uma retórica de ruptura a favor de um novo fazer gramatical.

De fato, isso se confirma, uma vez que Ribeiro (1881) afirma que

\begin{abstract}
a grammatica não faz leis e regras para a linguagem; expõe os factos della, ordenados de modo que possam ser aprendidos com facilidade. O estudo da grammatica não tem por principal objecto a correcção da linguagem. Ouvindo bons oradores, conversando com pessoas instruídas, lendo artigos e livros bem escriptos, muita gente consegue fallar e escrever correctamente sem ter feito estudo especial de um curso de grammatica (RIBEIRO, 1881, p. 1).
\end{abstract}

Podemos ver no trecho apresentado acima uma clara virada no tratamento retórico dado por este gramático para a noção de gramática. Não vemos mais uma visão de língua que desconsidera seus processos evolutivos, em que sua maior preocupação recai sobre a criação de regras e a correção de dados da língua.

$\mathrm{Na}$ verdade, percebe-se, retórica de ruptura com a gramática tradicional. Naquele momento (1881) não se vê mais gramática como a "arte do bom falar e escrever" (própria das gramáticas anteriores), mas sim como um fazer gramatical que não cria mais leis e regras para serem seguidas pela sociedade, pois o autor defende que a gramática deve expor e ordenar os fatos da linguagem para facilitar a aprendizagem de uma língua.

Porém, no que diz respeito ao tratamento retórico e gramatical dado à língua portuguesa do Brasil na gramática analisada, podemos perceber que o posicionamento das características próprias do português do Brasil tem lugar periférico no decorrer da obra. Muitas vezes este tratamento aparece como observações complementares às explicações centrais. Além disso, junto com essas explicações complementares dadas às especificidades do português do Brasil, é comum aparecer expressões pejorativas relacionadas ao "dialeto brasileiro", como: "é erro comezinho no Brazil" (p. 230).

A seguir, analisaremos a Grammatica Portugueza $-3^{\circ}$ anno, de João Ribeiro, para verificarmos o tratamento retórico dado pelo autor às especificidades da língua portuguesa do Brasil.

4.2 Grammatica Portugueza - $3^{\circ}$ anno (1889 [1887]), de João Ribeiro

A Grammatica Portugueza - $3^{\circ}$ anno, de João Ribeiro, publicada pela primeira vez em 1887, foi uma das gramáticas escritas com base nos moldes requeridos pelo programa de Fausto Barreto. Vale salientar que, apesar da nossa busca exaustiva, não obtivemos acesso à primeira edição da obra. Desta forma, aqui analisaremos a terceira edição da gramática, publicada no ano de 1889.

Iniciando a nossa análise da retórica apresentada pelo gramático, na parte inicial da obra, durante a seção "Lição I", Ribeiro (1889) discorre sobre a definição de gramática que seguirá. 
De acordo com o autor, "grammática é a coordenação das formulas, leis ou regras, segundo as quaes uma lingua é falada ou escrita" (p. 1). Ribeiro (1889 [1887]) complementa afirmando que "esta definição é deduzida da observação dos factos da linguagem" (p. 1).

Inicialmente, podemos perceber que o gramático já leva em consideração dados da língua falada e apresenta uma retórica de ruptura a favor de um fazer gramatical que toma como base a observação dos fatos da linguagem. É possível observar que esse argumento ganha força quando, após essa definição de gramática, Ribeiro (1889 [1887]) apresenta sua vinculação com o modelo gramatical histórico-comparativo e defende que

o estudo histórico como o comparativo são inseparáveis e constituem o methodo historico-comparativo, essencial à sciencia das línguas. No caso da língua portugueza, os elementos historicos são fornecidos pelo latim, pelo portuguez antigo e pelas influencias das linguas extranhas, em diversas épocas; os elementos comparativos acham-se na analyse das linguas romanas, o italiano, o francez, o hespanhol, que todas se originam do latim barbaro da edade-média (p. 2).

Diante disso, podermos verificar a vinculação do gramático com o paradigma gramatical histórico-comparativo e sua retórica de ruptura, mostrando que Ribeiro (1889 [1887]) estava ciente dos preceitos base desse modelo gramatical. De fato, isso se confirma quando consideramos que essas gramáticas foram produzidas para se adequarem ao programa de estudos de Fausto Barreto, que adotava claramente uma orientação histórico-comparativa (BORGES NETO, 2018).

Outro dado interessante retirado dessa gramática é que Ribeiro (1889 [1887]) reconhece as características próprias da língua portuguesa do Brasil. Segundo o gramático, o português do Brasil em relação ao português de Portugal apresenta "diferenças notaveis de prosodia e de syntaxe" (p. 306).

Contudo, podemos perceber que, como na gramática de Júlio Ribeiro, por exemplo, o posicionamento das especificidades do português do Brasil ocupa um lugar periférico no decorrer da obra. Estas especificidades aparecem como observações complementares das regras gramaticais explanadas. Junto com essas explicações complementares dadas às especificidades da língua portuguesa do Brasil, é comum aparecer expressões que as denigrem.

$\mathrm{Na}$ próxima seção, analisaremos as Noções de Grammatica Portugueza, de Manuel Pacheco da Silva Junior e Lameira de Andrade (1887), para observarmos o tratamento retórico dado pelo gramático às especificidades sintáticas do português do Brasil.

\subsection{Noções de Grammatica Portugueza (1887), de Manuel Pacheco da Silva Junior e Lameira} de Andrade

De acordo com Pacheco \& Lameira (1887), o projeto inicial da Noções de Grammatica Portugueza surgiu com objetivo inicial de "escrever uma grammatica completa da lingua portugueza, rompendo em lucta com a tradição" (p. 3). Contudo, os gramáticos afirmam que

O novo programma para os exames geraes de preparatórios, porem, veio fazer-nos mudar do propósito. E' que muitos dos pontos nelle exigidos para os exames de portuguez não se encontrando nas grammaticas que por ahi correm impressas, e os alumnos não tendo fontes onde possam haurir a instrucção de que carecem, resolvemos vir ainda uma vez em auxilio da mocidade estudiosa (p. 3).

Já na introdução da gramática podemos perceber a intenção inicial dos gramáticos de apresentar um fazer gramatical a fim de romper com a tradição gramatical da época. Porém, surgiu a necessidade de Pacheco \& Lameira (1887) se adequarem ao programa de Fausto 
Barreto, tendo, assim, que escrever uma gramática visando os exames preparatórios do Colégio Pedro II.

No início da obra, na "primeira lição", Pacheco \& Lameira (1887) apresentam a definição de gramática seguida pelos autores. De acordo com os gramáticos, "grammatica geral é o estudo dos factos e das leis da linguagem em toda sua extensão" (p. 5). Além disso, os gramáticos defendem que "grammatica geral é propriamente o estudo da linguagem (glottologia), isto é, o estudo dos meios extraordinariamente numerosos pelos quaes o genero humano, na diversidade das raças e na succeção dos tempos, exprimiu o pensamento" (p. 4).

Desta maneira, fica claro que os gramáticos já apresentam uma retórica de ruptura a favor de um fazer gramatical que considera a linguagem em toda sua extensão, além dos processos pelos quais a língua passa no decorrer do tempo. Indica-se, assim, um possível vínculo com o fazer gramatical histórico-comparativo.

Realmente, isso se confirma, uma vez que os gramáticos afirmam que

\begin{abstract}
Grammatica historica ou comparativa é a que emprega a historia e a comparação como instrumentos verificadores da linguagem. Só ella nos permite ensinar a dissecação scientifica dos vocabulos; permite remontar ao passado obscuro, muito além do ponto em que param a lenda e a tradição; pode reconstruir a fórma typica das palavras desconfiguradas ou gastas pela migração e pelos séculos (p. 6).
\end{abstract}

Como nas outras gramáticas aqui analisadas, podemos perceber uma mudança no tratamento retórico dado pelos gramáticos para a noção de gramática. Segundo Pacheco \& Lameira (1887), o fazer gramatical deve considerar a história e o elemento comparativo para verificar as regras da linguagem. Desta forma, através de uma retórica de ruptura, os gramáticos rompem com o modelo racionalista em relação à linguagem e ao objetivo do fazer gramatical.

Contudo, sobre o tratamento gramatical dado ao português do Brasil na gramática de Pacheco \& Lameira (1887), podemos perceber que o posicionamento das menções sintáticas da língua portuguesa do Brasil tem lugar periférico na obra. As poucas menções apresentadas pelos gramáticos aparecem como observações complementares às explicações centrais.

\title{
5 A análise do nível descritivo: observando os dados sintáticos do português do Brasil
}

Nas seguintes subseções analisaremos o nível gramatical das obras, ou seja, será observado se as menções das especificidades sintáticas da língua portuguesa do Brasil da nossa periodização são apresentadas de maneira neutra (descritiva), positiva ou negativa (valorativas). Além disso, verificaremos se há compatibilidade com o fazer gramatical proposto em nível retórico.

\subsection{Grammatica Portugueza (1881), de Júlio Ribeiro}

Nesta obra foram mapeadas seis (06) referências ao português do Brasil em nível sintático. A seguir, apresentaremos a análise de tais excertos para interpretarmos como Ribeiro (1881) expõe as especificidades sintáticas do português do Brasil do período.

Excerto 1 - Sentenças interrogativas em que se pospõe o pronome sujeito ao verbo (RIBEIRO, 1881)

Nas sentenças interrogativas pospõe-se o pronome sujeito ao verbo, ex.: "Queres TU vir almoçar comigo? ». 
Cumpre notar que, principalmente no Brazil, vai-se estabelecendo o uso de construir as sentenças interrogativas em ordem direita, deixando-se o seu sentido de pergunta a cargo somente da inflexão da voz, ex.: «TU queres vir almoçar comigo? ». (p. 221)

Neste excerto, o primeiro retirado da obra, pudemos perceber que o autor, ao discorrer sobre a colocação dos pronomes sujeito em relação ao verbo, detém-se a realizar apenas uma descrição do fato linguístico exposto, não o apresentando, assim, de maneira necessariamente negativa ou positiva.

Vale apontar que, nesse excerto, Ribeiro (1881) apresenta que este uso está se estabelecendo em solo brasileiro, justificando, assim, sua gramatização. Desta forma, neste caso o gramático está seguindo a retórica apresentada na apresentação da obra, corroborando um novo fazer gramatical.

Para verificarmos se Ribeiro (1881) continua não proibindo o uso de dados sintáticos do português do Brasil, seguindo a noção de gramática apresentada por ele, passemos ao próximo excerto:

Excerto 2 - Pronome acusativo em relação subjetiva (RIBEIRO, 1881)

E' erro vulgar no Brazil usar-se em casos taes da relação subjectiva; diz-se, por exemplo, «Vi ELLE caminhar ás pressas-Deixa ELLE ir » (p. 228).

Diferentemente do excerto analisado anteriormente, Ribeiro (1881) adota uma postura proibitiva sobre o uso do pronome acusativo em relação subjetiva característico da língua portuguesa do Brasil.

Isso fica evidente quando o gramático define como 'erro vulgar' esta especificidade sintática utilizada no Brasil, tomando como referência o português lusitano, ignorando, assim, as especificidades da língua que aqui se constituía (cf. VIEIRA, 2018; BORGES NETO, 2018). Além disso, é possível perceber ausência de justificativas para embasar esta proibição.

Desta forma, o autor se contradiz aplicando juízo de valor numa especificidade do português do Brasil, não seguindo a retórica exposta na apresentação da sua gramática, uma vez que este defende que a língua evolui e que é papel do gramático descrever as regras que regem tal evolução.

Verificaremos o próximo excerto para observarmos como Ribeiro (1881) apresentará o uso do pronome oblíquo mim na língua portuguesa do Brasil.

Excerto 3 - Uso do pronome oblíquo mim no português do Brasil (RIBEIRO, 1881)

Em taes casos usa-se da relação subjectiva, ex.: « Esta laranja é para EU comer ». No Brazil peccase contra este preceito dizendo-se « Para MIM comer, etc.» (p. 228).

Como no excerto analisado anteriormente, mais uma vez, Ribeiro (1881) proíbe fortemente o uso desta especificidade sintática própria da língua portuguesa do Brasil. O autor utiliza-se da expressão "pecca-se" ao se referir a esta construção sintática que é comumente utilizada, até hoje, pelo povo brasileiro. Além da proibição e do não cumprimento da sua retórica, novamente, o gramático não apresenta uma justificativa para tal proibição.

Ribeiro (1881) não se restringe a descrever esta especificidade da língua portuguesa do Brasil, como esperado de uma obra que se propõe a apresentar um fazer gramatical que considera os processos evolutivos da língua. Além de apresentar regras que proíbem o uso de tal especificidade, o autor utiliza expressões pejorativas para denegrir o uso.

Disto isso, passaremos para a análise do próximo excerto: 
Excerto 4 - Uso de pronome substantivo em relação subjetiva no português do Brasil (RIBEIRO, 1881)

Pôr em relação subjectiva o pronome substantivo que serve de objecto a um verbo é erro comezinho no Brazil, até mesmo entre os doutos: ouvem-se a cada passo as locuções incorrectas «Eu vi elleEspere eu » (p. 230).

Diante da análise deste excerto foi possível identificar que, mesmo com a utilização desta construção sintática pelos considerados "doutos", ou seja, a elite intelectual brasileira, o autor ainda apresenta esta característica da língua portuguesa do Brasil como 'erro comezinho', mostrando, mais uma vez, que o autor não rompe com o fazer gramatical tradicional, que entende o português de Portugal e o do Brasil como unidade, ignorando e proibindo, assim, as especificidades da língua portuguesa do Brasil.

Como na proibição comentada anteriormente, Ribeiro (1881) não apresenta uma justificativa para sua proibição, apesar de entender que este uso já é feito pela comunidade letrada. Assim, o autor contradiz a sua própria retórica com o fazer gramatical purista.

Daremos continuidade analisando o uso do verbo haver com significado de ter, especificidade sintática do português do Brasil, e observaremos se o gramático descreverá ou proibirá tal uso.

Excerto 5 - Substituição do verbo haver por ter no português do Brasil (RIBEIRO, 1881)

Substituem tambem ter a haver e dizem: « TEM muita gente na igreja-Agora TEM muito peixe no tanque ». Este uso vai-se tornando geral no Brazil até mesmo entre as pessôas illustradas (p. 257).

Divergindo dos dois últimos excertos aqui analisados, através da análise deste excerto podemos ver que Ribeiro (1881) apresenta esta especificidade sintática da língua portuguesa do Brasil de maneira descritiva, relacionando-a a classes prestigiadas da sociedade brasileira e não aplicando juízo de valor negativo sobre a expressão.

Como no excerto anterior, o autor aponta novamente que esta especificidade estava sendo utilizada por pessoas letradas e de alta posição social, porém ainda não é explicitamente apresentada como modelo a ser seguido.

Diferentemente dos excertos anteriores, Ribeiro (1881) apenas apresenta este uso do português do Brasil. Vale salientar, que, apesar de apresentar este fato através de descrição, o autor utiliza-se majoritariamente de uma visão purista que, na maioria das vezes, apenas descreve as especificidades do português do Brasil para apresentá-las como de uso impróprio ou incorreção gramatical.

Feita essa explanação, passaremos para a análise do último excerto retirado da obra: Excerto 6 - Uso de dupla negativa no português do Brasil (RIBEIRO, 1881)

Em algumas provincias do Brazil, como Bahia, Minas, não duplica-se, ex.: « NÃO posso, NÃO. NÃO dou, NÃO ». Nas sentenças exclamativas não emprega-se como particula intensiva para reforçar a expressão, ex.: « Quantos a estas horas NÃO estão mortos! - (p. 260).

Como no excerto anterior, Ribeiro (1881) descreve uma especificidade da língua portuguesa do Brasil, mas não aplica juízo de valor sobre esta. Ao falar sobre o uso da dupla negativa, especificidade da língua portuguesa do Brasil que já é aceita por algumas gramáticas dos linguistas da contemporaneidade, o autor detém-se a falar que este uso acontece em algumas províncias brasileiras.

Podemos perceber que esta gramática se difere, no nível retórico, das gramáticas produzidas anteriormente. Ribeiro (1881) discute o fazer gramatical na apresentação da sua 
gramática como exposição dos dados linguísticos e de como estes se ordenam. Porém, isto fica apenas no nível retórico. O autor segue utilizando o português lusitano como mirante de gramatização, mesmo com a transição do modelo racionalista para o um novo fazer gramatical. Além disso, esta gramática segue exemplos retirados da literatura clássica e criando/expondo regras puristas para reger o uso do português, ignorando as especificidades do português do Brasil.

Na próxima secção analisaremos a Grammatica Portugueza - $3^{\circ}$ anno, de João Ribeiro, para verificarmos como foram feitas as menções sintáticas da língua portuguesa do Brasil na obra.

\subsection{Grammatica Portugueza - $3^{\circ}$ anno (1889 [1887]), de João Ribeiro}

O mapeamento dos dados sintáticos do português do Brasil nesta obra revelou um quantitativo de sete (07) referências. Analisaremos estas referências para interpretarmos como o autor da gramática, Ribeiro (1889 [1887]), apresenta estas menções.

Excerto 7 - Uso de pronome relativo no português do Brasil (RIBEIRO, 1889 [1887])

A expressão $\mathrm{O}$ que é a vida? com anteposição do pronome o, é provavelmente um brasileirismo. $\mathrm{O}$ uso clássico não admitte anteposição do o. Os bons escriptores contemporâneos confirmam a omissão: Mulher, que me pedes tu? (Al. Herculano, Arrhas, VIU). A mesma syntaxe é observada nas linguas romanas. (1)', (p. 238).

Após a análise deste primeiro excerto retirado da gramática de Ribeiro (1889 [1887]), observa-se que o gramático ao tratar sobre o uso dos brasileiros do pronome demonstrativo $o$ em anteposição do pronome interrogativo que, o julga como incorreção, em outras palavras, um brasileirismo. Vale apontar, entretanto, que a justificativa apresentada pelo autor para a proibição deste uso é o uso de escritores clássicos da língua portuguesa de Portugal. Desconsiderando, assim, as diferenças sintáticas entre as línguas defendidas pelo gramático no início da sua obra.

Assim, apesar de Ribeiro (1889 [1887]) apresentar sua gramática como pertencente ao modelo histórico-comparativo, o gramático se contradiz ao desconsiderar os processos evolutivos da língua e contesta estes processos apresentando exemplos clássicos da literatura.

A partir desse momento, todos os excertos que serão analisados foram retirados da seção intitulada "Brazileirismos" (p. 307), de modo que, para evitar repetições, resolvemos analisálos de uma só vez.

Segundo Ribeiro (1889 [1887]), "os brazileirismos syntacticos consistem em construcções divergentes do cunho do vernaculo". E, como podemos observar no exemplo analisado anteriormente, os brasileirismos são vistos como incorreções gramaticais cometidas pelos brasileiros, tomando como base a gramática da língua portuguesa de Portugal, e que devem ser evitadas.

Tendo esta definição em mente, passaremos para a análise dos dados.

Excerto 8 - Sistematização dos brasileirismos sintáticos (RIBEIRO, 1889 [1887])

1. O emprego do pronome lhe, como objectivo:

Amo-lhe $=$ Amo-o (p. 309).

2. O emprego do pronome elle, como objectivo:

Vi elle $=$ Vi-o (p. 309).

4. A anteposição indébita dos pronomes-complementos: 


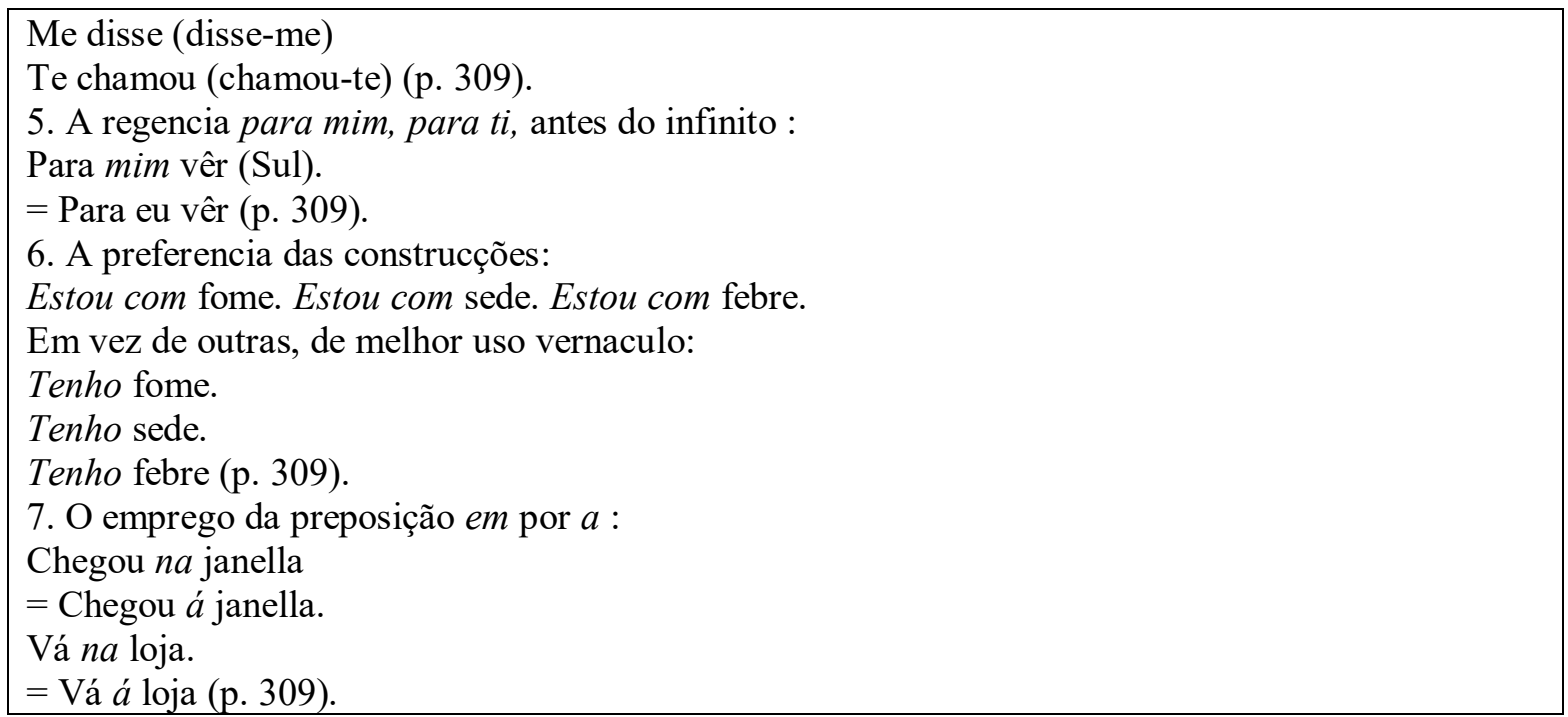

Como já esperado, uma vez que estes foram extraídos de uma seção de caráter periférico, intitulada "brazileirismos", todos os dados sintáticos do português do Brasil aqui expostos são apresentados por Ribeiro (1889 [1887]) com caráter de proibição, não divergindo da postura adotada no excerto anterior.

Desta forma, após a análise do oitavo excerto, é observável que, apesar de o autor se propor a fazer uma gramática aos moldes histórico-comparativos, ou seja, considerando os aspectos evolutivos da língua ao decorrer da história a fim de descrevê-los, através "da observação dos factos da linguagem" (p. 1), Ribeiro (1889 [1887]) continua apresentando o português de Portugal como mirante de gramatização, mesmo após uma retórica de ruptura com o modelo racionalista.

Após a realização desta análise de nível gramatical, chegamos à conclusão que esta gramática continua seguindo a tradição gramatical, e continua utilizando-se de exemplos retirados da literatura, além de ditar regras para reger os usos sintáticos do português do Brasil com base no português lusitano, ignorando, assim, as especificidades sintáticas que aqui se constituía.

5.3 Noções de Grammatica Portugueza (1887), de Manuel Pacheco da Silva Junior e Lameira de Andrade

Nesta obra foi mapeado um total de duas (02) menções ao português do Brasil em nível sintático. A seguir, analisaremos tais menções para interpretarmos como Pacheco \& Lameira (1887) discute as especificidades sintáticas da língua portuguesa do Brasil na obra.

Excerto 9 - O uso de pronome em relação objetiva em inícios de frase no português do Brasil (PACHECO \& LAMEIRA, 1887)

4 - Não se deve começar uma oração pelo pronome em relação objectiva (me parece, te disse, lhe fallei). O povo (no Brazil) conserva-se, porem aí ferrado ás formas procliticas, que ainda são correntes no hesp. e no ital. (p. 493).

Pacheco \& Lameira (1887), ao discorrer sobre a colocação de pronome em relação objetiva no início de frases do português do Brasil do final do século XIX, condenam esta característica do português do Brasil, uma vez que afirmam que "não se deve" fazer uso desta 
Volume 15 - Número 1 - jan/jul de 2020

especificidade. Para justificar tal proibição, os gramáticos se utilizam do comparativo entre línguas.

Desta forma, podemos verificar que os gramáticos utilizam o elemento comparativo, oriundo da gramática histórico-comparativa, para condenar o uso desta especificidade sintática do português do Brasil.

Excerto 10 - O emprego da preposição em e do pronome sujeito pelo objeto no português do Brasil (PACHECO \& LAMEIRA, 1887)

Differenças Syntaxicas importantes [entre o português do Brasil e o português de Portugal] são raras, e apenas na linguagem vulgar: - fui na casa, estava na janella; o emprego do pronome sujeito pelo objecto - vi elle, e tambem vi-lhe, isto é para mim ler (p. 511).

Neste excerto, Pacheco \& Lameira (1887) apresentam duas especificidades do português do Brasil (o uso da preposição em por $a$ e o emprego do pronome sujeito pelo objeto). Contudo, como no exemplo apresentado anteriormente, os gramáticos apresentam as duas especificidades do português do Brasil e condenam o seu uso, julgando-as como "linguagem vulgar”. Apesar da proibição proposta pelos gramáticos, nenhuma justificativa é apresentada para tal.

Deste modo, quando comparamos como o excerto analisado anteriormente, confirmase que a mudança do fazer gramatical apresentada pelos gramáticos continua apenas no nível retórico.

Depois de analisarmos as menções extraídas da gramática de Pacheco \& Lameira (1887), podemos verificar que, apesar dos gramáticos se proporem a "escrever uma grammatica completa da lingua portugueza, rompendo em lucta com a tradição" (p. 3), não rompem com a tradição gramatical.

Isso fica claro, uma vez que Pacheco \& Lameira (1887) preocupam-se apenas em prescrever regras, condenando os usos do português do Brasil com base na tradição gramatical, proibindo todos os usos das especificidades sintáticas aqui citadas. Além disso, é observável que os gramáticos não se preocupam em justificar as razões que regem a proibição dos usos sintáticos aqui apresentados, desconsiderando, assim, os processos históricos e sociais que influenciaram o estabelecimento desses usos que se constituíam no Brasil.

\section{Palavras finais}

A partir da análise das gramáticas selecionadas para este estudo é perceptível a produção de uma metalinguagem sob influência da tradição descritivo-normativa greco-latina e a presença da literatura clássica da língua portuguesa de Portugal como referência para a criação de regras para guiar os usos sintáticos do português do Brasil, provocando, assim, uma contradição entre a retórica de ruptura adotada pelos gramáticos e o fazer gramatical realizado. Acreditamos que este não rompimento ocorreu por dois principais motivos: 1) pelo modelo ter surgido na periodização adotada na nossa pesquisa (1880-1890), ou seja, os gramáticos aqui apresentados foram formados dentro do modelo filosófico; e 2) pela clara preocupação dos gramáticos em produzir obras com fins pedagógicos.

Desta forma, é plausível afirmamos que o não rompimento total dos gramáticos do período científico com a corrente anterior está diretamente relacionado com a formação que estes obtiveram dentro do modelo filosófico e a sua relação com o tempo.

Além disso, é viável apontar que a gramatização de especificidades de dados da língua portuguesa do Brasil parte de um processo amplo, este sujeito a influências dos meios linguísticos e históricos. Nesse contexto, devemos entender que as gramáticas aqui analisadas são produtos de estudos sobre a língua portuguesa desenvolvidos no decorrer do tempo. Deste 
modo, apesar de uma tentativa de rompimento em relação ao fazer gramatical filosófico, fica clara a falha dos gramáticos em executar o que foi proposto. Isso reflete diretamente no tratamento dado às especificidades da língua portuguesa do Brasil, uma vez a maioria das menções feitas são de caráter marginal, como em seções voltadas para discutir vícios de linguagem, além da utilização de expressões para combater tais usos.

Em síntese, podemos perceber uma tentativa de todos os gramáticos em enquadrar-se na nova corrente gramatical que surgia no final do século XIX, estes motivados por aspectos políticos e linguísticos. Entretanto, após a análise dos dados sintáticos retirados das obras aqui analisadas, é bastante perceptível que estes mesmos gramáticos falham em seus propósitos declarados e não conseguem efetivamente apresentar um fazer gramatical nos moldes do modelo histórico-comparativo, ao menos não nesses instrumentos.

\section{Referências}

ALBUQUERQUE, J. G de; COX, M. I. P. A polêmica entre separatistas e legitimistas emtorno de língua do Brasil na segunda metade do século XIX. Polifonia, EdUFMT, n. 3, p. 31-59, 1997.

AUROUX, S. A revolução tecnológica da gramatização. Tradução de Eni Puccinelli Orlandi. Campinas: Editora da Unicamp, 1992.

BORGES NETO, J. História da Gramática. Curitiba, 2018. (Mimeo).

CAVALIERE, R. A gramática no Brasil: ideias, percursos e parâmetros. 1 ed. Rio de Janeiro: Lexikon, 2014.

COELHO, O. F.; DANNA, S. M. D. G.; POLACHINI, B. S. O português do Brasil em gramáticas do século XIX. Confluência - Revista do Instituto de Língua Portuguesa. Rio de Janeiro, n. 46, p. 115$141,2014$.

MURRAY, S. Theory groups and the study of language in North America: a social history. Amsterdam/Philadelphia: John Benjamins, 1994.

PACHECO, M; LAMEIRA, B. P. Noções de grammatica portugueza de acordo com o programma oficial para os exames geraes de preparatórios do corrente anno. 1 ed. Rio de Janeiro. 1887.

RIBEIRO, J. Grammatica Portugueza. 1 ed. 1881.

RIBEIRO, J. Grammatica Portugueza - 3 anno. 3 ed. Rio de Janeiro. 1889.

SWIGGERS, P. A historiografia da linguística: objeto, objetivos, organização. Revista Confluência, n. 44-45, p. 39-59, 2013.

SWIGGERS, P. La historiografía de la lingüística: apuntes y reflexiones. Revista Argentina de

Historiografia Lingüística. Buenos Aires, vol. 1, n. 1, p. 67-76, 2009.

VIEIRA, Francisco Eduardo. A gramática tradicional: história crítica. São Paulo: Parábola Editorial, 2018.

Submetido em $02 / 05 / 20$

Aceito em 18/08/20 